\title{
Endothelial function of normotensive adolescents with no risk factors for arterial hypertension
}

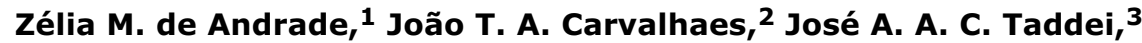 \\ Dejaldo M. J. Christofalo, ${ }^{4}$ Sergio A. Ajzen ${ }^{5}$
}

\begin{abstract}
Objective: To define standards for normal endothelial function in adolescents by high-resolution ultrasound measurement of endothelium-dependent vascular dilatation.

Methods: This was a cross-sectional, descriptive, observational study and part of the thematic project "Clinical Study of Growth, Behavior, Arterial Hypertension, Obesity and Oral Health" (ECCCHOS) that was developed by the Discipline of Nutrition at the Universidade Federal de São Paulo. Thirty-one adolescents, eight male and 23 female, with no risk factors for systemic arterial hypertension were selected from 1,420 high-school students. The students were daytime pupils at a school in the southeastern district of the city of São Paulo, the capital of São Paulo state, located in the Southeast region of Brazil. All results are presented in the form of means with standard deviations and percentiles.

Results: For male students, endothelium-dependant dilation 90 seconds after the cuff was released was $20.9 \pm 6,7 \%$ [mean \pm 1 standard deviation] with a 10th percentile of 12.5 and for females these figures were $18.8 \pm 12.9 \%$ with a 10 th percentile of $6.6 \%$. Values for the whole group of subjects were $19.3 \pm 11.7 \%$ and $6.7 \%$, respectively.

Conclusion: Endothelium-dependant vascular dilation of $6.7 \%$, after 90 seconds, which corresponds to the 10 th percentile, can be considered the lower limit of normality for this age group. Knowledge of this limit is important for the diagnosis of endothelium dysfunction that appears before cardiovascular disease.
\end{abstract}

J Pediatr (Rio J). 2005;81(5):395-9: Adolescents, endothelium, and ultrasound.

\section{Introduction}

The endothelium is one of the largest and most complex organs, with more than $1 \times 10^{12}$ cells and weighing roughly the same as the liver. ${ }^{1}$ It was only in 1977 that the endothelium ceased to be considered as merely a layer of inert cells that cover the luminal surface of vessels. From that date onwards discoveries were made of its importance to the control of vascular tone, to coagulation and to the growth of vessels, in addition to its specific roles within each organ, such as in gaseous exchange in the lungs, in the control of myocardial functions and of phagocytosis in the liver and spleen. ${ }^{2}$ In the kidneys, it is vascular endothelial growth factor that induces elevated permeability to water, a characteristic of glomerular endothelium. ${ }^{3}$ Endothelium is an active participant in metabolic processes, plays and important role in controlling platelet activation and produces vasodilators such as endothelium-derived relaxing factor (EDRF), nitric oxide (NO) and prostacyclin, in addition to vasoconstrictors such as endothelin. ${ }^{4}$

1. MD. PhD student, Department of Pediatrics, Universidade Federal de São Paulo - Escola Paulista de Medicina (UNIFESP-EPM), São Paulo, SP, Brazil.

2. PhD. Professor. Chief of the Pediatric Nephrology Sector of the Department of Pediatrics, UNIFESP-EPM, São Paulo, SP, Brazil.

3. PhD. Professor. Chief of the Discipline of Nutrition of the Department of Pediatrics, UNIFESP-EPM, São Paulo, SP, Brazil.

4. PhD. Departament of Imaging Diagnosis, UNIFESP-EPM, São Paulo, SP, Brazil.

5. Professor. Coordinator of the Radiology and Radiologic Sciences Graduation Program, Department of Imaging Diagnosis, UNIFESP-EPM, São Paulo, SP, Brazil.

Financial support: Fundação de Amparo à Pesquisa do Estado de São Paulo - FAPESP - 02/13827-6R.

Manuscript received Jun 29 2004, accepted for publication Apr 132005.

Suggested citation: de Andrade ZM, Carvalhaes JT, Taddei JA, Christofalo DM, Ajzen SA. Endothelial function of normotensive adolescents with no risk factors for arterial hypertension. J Pediatr (Rio J). 2005;81: 395-9. 
Endothelial injury is the dominant factor in the production of thrombosis and is crucial in the genesis of atherosclerosis and arterial hypertension and, irrespective of cause, exposes collagen, which promotes platelet activation and adhesion, triggering the coagulation process. Platelets adhere to the extracellular matrix by means of the von Willebrand factor. Prostacyclin and NO impede platelets from adhering to normal endothelium. ${ }^{5}$

Studies have found evidence of abnormal endothelial function in people with risk factors for arterial hypertension and atherosclerosis, such as obesity, familial hypercholesterolemia, family history of arterial hypertension and low birth weight. ${ }^{6-8}$ These studies assessed endothelial function by means of high-resolution B-mode ultrasound, a methodology that is widely used to evaluate endotheliumdependent vascular dilatation. This dilatation is a function of NO, which is a potent vasodilator and is produced by endothelial cells in response to stimulation from blood in contact with the vessel walls. A reduction in this response signifies reduced NO production, which is a sign of endothelial abnormality and takes place before the appearance of systemic arterial hypertension, atherosclerosis and other cardiovascular diseases.

Endothelial function assessment, performed by the noninvasive method of high-resolution ultrasound, produces precise and reproducible results. ${ }^{9}$ Based on the principle that all procedures, whether diagnostic or therapeutic, should produce the best results with the least side effects, such as causing pain and organic injuries, this methodology can be considered extremely useful for programs aiming to prevent diseases that make up the metabolic insulin resistance syndrome - Syndrome $X$. In this syndrome, obesity and dyslipidemia in childhood and adolescence generate hypertension during adulthood. ${ }^{10}$

The literature investigated did not provide standards for normal endothelial function in adolescents assessed by high-resolution ultrasound. This being so, an assessment of the endothelial function of adolescents with no risk factors could define these standards of normality and it is this that was the objective of the present study.

\section{Patients and methods}

This is a descriptive, observational and cross-sectional study, part of the thematic project "Clinical Study of Growth, Behavior, Arterial Hypertension, Obesity and Oral Health" (ECCCHOS) that was developed by the Discipline of Nutrition at the Universidade Federal de São Paulo - Escola Paulista de Medicina (UNIFESP-EPM).

The project was approved by the Committee for Ethics in Research at UNIFESP-EPM and given reference number 0599/02.

During the months from June to December 2002, trained physicians specializing in pediatrics and nutrition, weighed and measured 1,420 adolescents born between March 11 1984 and September 17 1987. This was 98.68\% of the students registered to attend the daytime classes at a public high school in the city of São Paulo, capital of the state with the same name, in the Southeast region of Brazil. Three hundred and forty of these 1,420 individuals were eligible for the ECCCHOS project. These 340 were chosen in the following manner: adolescents were summoned by class and were weighed and measured in the order that they arrived. When an obese or overweight subject was identified, the next well-nourished subject, paired for age and sex with the overweight or obese one was selected. The same was done when an individual with small stature was identified, the next well-nourished student, paired for age and sex was selected. Anthropometric (weight and stature) assessment was performed and blood pressure measured ${ }^{11}$ at the school during the periods set aside for physical education in accordance with procedures recommended for fieldwork. ${ }^{12}$ Parents or guardians attended the school and were informed of the study objectives and provided information about the weight and stature of the adolescents at birth, chronic and familial diseases and nutritional habits. When the biological parents attended, weight, stature and blood pressure were measured. These measurements were taken using the same measurements described for the adolescents. The parents or guardians and the adolescents provided signed authorization in order to take part. The participating adolescents had systemic, systolic and diastolic blood pressures below the 95th percentile of blood pressure for their percentile of stature for age $\mathrm{e}^{11}$ and were at Tanner puberty stages 4 or $5 .{ }^{13}$ None of the adolescents had an acute or chronic disease and neither had they suffered from any prior pathological processes that could have interfered with their physical development (rickets, hypothyroidism, growth hormone deficiency, Cushing's syndrome, renal insufficiency). Seventy-eight of the 340 adolescents selected were excluded for being obese or overweight and 38 were excluded for short stature. In addition to these, seven were excluded because they refused to have their blood pressure taken or were hypertensive, eight because they had had birth weights of less than $2,500 \mathrm{~g}, 77$ because they did not continue follow-up, 33 did not attend for endothelial function assessment, even after repeated appointments were made. The parents of 53 adolescents were either hypertensive or did not attend for blood pressure measurement. Four adolescents had hypothyroidism, one had elevated cholesterol and 10 had increased lipoprotein-A. After these exclusions the 31 adolescents that make up the present study remained.

Total cholesterol (TC), HDL cholesterol (HDL-C) and triglycerides (TG) were assayed by the enzymatic colorimetric method (Ópera, Bayer, USA). The LDLcholesterol (LDL-C) sub-fraction was obtained by applying Friedewald's equation: $\mathrm{LDL}-\mathrm{C}=(\mathrm{TC}-\mathrm{HDL}-\mathrm{C}+\mathrm{TG} / 5)$. Glycemia, creatinine and urea were measured using automated Ópera Bayer apparatus. The enzyme activities of glutamic oxaloacetic transaminase (GOT/AST), glutamic pyruvic transaminase (GPT/ALT), and gamma-glutamyl transferase were studied using Dialab reagents (Germany). Both TSH and free T4 were assayed using competitive enzyme immunoassay with AIA-PACK TSH reagents. Nephelometry was used for assays of lipoprotein-A, apolipoprotein-A, and apolipoprotein-B. 
Endothelium assessments were performed at the Fundação Oswaldo Ramos Kidney and Hypertension Hospital, a supplementary service of the UNIFESP-EPM, and employed high-resolution B-mode ultrasound, utilizing techniques that have been described previously. ${ }^{6}$ The equipment used for ultrasound was a digital, twodimensional HDI-3000 model, equipped with a 7-9 MHz linear transducer and manufactured by ATL Ultrasound, Inc. (Bothell, WA, USA). Examinations were performed in an air-conditioned room at an ambient temperature of around $22^{\circ} \mathrm{C}$. In order to avoid circadian variations, all examinations took place during the morning.

The lower limit for normality was set at the 10th percentile for endothelium-dependent dilatation, based on studies by Järvisalo et al. who suggest this value. ${ }^{14,15}$ There are no other studies on medical literature indexes that define standards for normal endothelial function in adolescents.

\section{Results}

Table 1 shows characteristics of the adolescents studied, with ages of around 16 years, and systolic and diastolic pressure levels within normal limits ${ }^{11}$ and body mass indices (BMI) below the 85th percentile, for both males and females. ${ }^{16}$ Results from biochemical blood assays were all within normal limits according to the methodologies employed.

Table 2 shows mean values and their respective standard deviations (SD) for BMI and pressure levels of the adolescents' mothers and fathers. Pressure values were all within normal limits ${ }^{17}$ and BMI results revealed a population with a large proportion of well-nourished adults and a few moderate obesity cases (BMI $>30$ and $<40$ ).

Table 3 shows that, for the male adolescents, the percentage of endothelium-dependent vascular dilatation 90 seconds after the cuff was released was $20.9 \pm 6.7 \%$, while for the 23 females this was $18.8 \pm 12.9 \%$. When all 31 adolescents are taken in conjunction, the mean dilatation

Table 1 - Distribution of birth weight, age, pressure levels and body mass indices (BMI) of the 31 adolescentes without risk factors for systemic arterial hypertension according to gender

\begin{tabular}{|c|c|c|}
\hline Variables & $\begin{array}{l}\text { Male sex } \\
(n=8)\end{array}$ & $\begin{array}{c}\text { Female sex } \\
(n=23)\end{array}$ \\
\hline Birth weight (kg) & $3.4 \pm 0.5$ & $3.2 \pm 0.5$ \\
\hline Ages (years) & $16 \pm 0.81$ & $6.3 \pm 1.1$ \\
\hline SAP $(\mathrm{mmHg})$ & $104.6 \pm 4.8$ & $97 \pm 10.5$ \\
\hline $\mathrm{DAP}(\mathrm{mmHg})$ & $65.4 \pm 6.1$ & $63 \pm 6.7$ \\
\hline BMI (weight/hight²) & $20.5 \pm 2.6$ & $20.3 \pm 1.8$ \\
\hline
\end{tabular}

Values expressed in mean \pm standard deviation.

SAP = Systolic arterial pressure in millimeters of mercury; DAP = Diastolic arterial pressure in millimeters of mercury; $\mathrm{BMI}=$ body mass index.
Table 2 - BMI and pressure levels of adolescent's mothers and fathers

\begin{tabular}{lcc}
\hline Variables & $\begin{array}{c}\text { Male sex } \\
(\mathbf{n}=\mathbf{8})\end{array}$ & $\begin{array}{c}\text { Female sex } \\
(\mathbf{n}=\mathbf{2 3})\end{array}$ \\
\hline BMI father & $24.7 \pm 4.1$ & $25.7 \pm 3.1$ \\
BMI mother & $24.4 \pm 4.3$ & $24.2 \pm 5$ \\
SAP father & $118.9 \pm 10.7$ & $118.4 \pm 7.2$ \\
DAP father & $71.9 \pm 8.4$ & $78.4 \pm 4.6$ \\
SAP mother & $110.6 \pm 10.1$ & $113 \pm 11.5$ \\
DAP mother & $70.6 \pm 9.4$ & $74.3 \pm 7.9$
\end{tabular}

Values expressed in mean \pm standard deviation.

$\mathrm{BMI}=$ body mass index; SAP = Systolic arterial pressure in millimeters of mercury; DAP = Diastolic arterial pressure in millimeters of mercury.

percentage and its respective SD is $19.3 \pm 11.7 \%$ and the 10 th percentile is at $6.7 \%$.

\section{Discussion}

The present study only enrolled adolescents at Tanner sexual maturation stages 4 and $5 .{ }^{13}$ In line with the stated objective of contributing to defining standards of normality for endothelium-dependent vascular dilatation, we found a percentage variation in diameter 90 seconds after removal of the cuff that was greater than has been reported in other studies. However, all of these had patient samples that differed from ours, in particular in terms of age groups. $6,18-28$

While the studies found in the literature employed similar methodology for endothelial function assessment, the employed patient samples which, in addition to including individuals from wider age ranges than the age range of the adolescents in our study, also differ by not having exclusion criteria that could demonstrate that the patient sample was free from metabolic or functional bias.

Singhal et al., studying the influence of rate of growth at 2 weeks postpartum on the endothelial function of adolescents at Tanner puberty stages 4 and 5 and aged between 13 and 16 years, found a mean flow-mediated vascular dilatation of $6.1 \pm 2.8 \mathrm{SD}$ in their control group. This value is lower than the figure found in our study, despite the ages of the adolescents being close. The study did not exclude patients with first degree relatives with cardiovascular disease. ${ }^{25}$

Järvisalo et al., studying 105 individuals aged 9 to 16 years, found that for the 24 subjects with the lowest weights, lowest body mass index and smallest diameter brachial arteries, there was a greater time interval [mean of 104 seconds \pm 1 SD ( 40 seconds)] between releasing the cuff and peak vascular dilatation. ${ }^{14}$ For the other 81 subjects, the mean for the same interval was 72 seconds \pm 1 SD (27 seconds). Our study assessed dilatation 90 seconds after the cuff was released, a point between the two values in the research cited above. ${ }^{14}$ 
Table 3 - Ultrasound assessment of the endothelial function

\begin{tabular}{|c|c|c|c|}
\hline Variables & $\begin{array}{c}\text { Male sex } \\
(n=8)\end{array}$ & $\begin{array}{l}\text { Female sex } \\
\quad(n=23)\end{array}$ & $\begin{array}{c}\text { Total } \\
(\mathbf{n}=\mathbf{3 1})\end{array}$ \\
\hline Pre flow* $\mathrm{ml} / \mathrm{min}$ & $19.5 \pm 14.8$ & $15.5 \pm 13.9$ & $16.5 \pm 14.6$ \\
\hline $15^{\prime}$ flow $^{\dagger}(\%)$ & $1,833.5 \pm 1,239.1$ & $1,615.9 \pm 1,468.9$ & $1,672 \pm 1,396.4$ \\
\hline $90 "$ flow $\neq(\%)$ & $270.2 \pm 229.9$ & $254.1 \pm 368.6$ & $258.3 \pm 334.7$ \\
\hline Pre diameter $\S(\mathrm{mm})$ & $3.3 \pm 0.6$ & $2.8 \pm 0.5$ & $2.9 \pm 0.6$ \\
\hline 15" diameter i (\%) & $1.9 \pm 6.9$ & $-0.6 \pm 7.5$ & $0.1 \pm 7.3$ \\
\hline 90 " diameter " (\%) & $20.6 \pm 6.7$ & $18.8 \pm 12.9$ & $19.3 \pm 11.7 * *$ \\
\hline
\end{tabular}

Values in mean \pm 1 standard deviation.

* Arterial blood flow in milliliters/minutes, before the cuff is inflated.

$\dagger$ Percentage of arterial blood flow increase, 15 seconds after the cuff is released, as compared to the flow before the cuff is inflated.

¥ Percentage of arterial blood flow increase, 90 seconds after the cuff is released, as compared to the flow before the cuff is inflated.

$\S$ Artery diameter, in millimeters, before the cuff is inflated.

Percentage of arterial diameter increase, 15 seconds after the cuff is released, as compared to the flow before the cuff is inflated.

I Percentage of the artery diameter increase, 90 seconds after the cuff is released, as compared to the flow before the cuff is inflated.

** The 10 th percentile of vascular dilation was $6.7 \%$.

In a different study, Järvisalo et al., ${ }^{14}$ compared the endothelial function of children with type 1 diabetes with the endothelial function of healthy children with mean age of $11 \pm 2$ years (mean $\pm 1 S D$ ). Mean peak vascular dilatation among the diabetic patients was $4.4 \% \pm 1$ SD (3.4\%) and among the healthy children the mean was $8.7 \% \pm 1 \mathrm{SD}$ (3.6\%). They defined the lower limit of normality as being the 10th percentile of the percentage difference between the diameters before and after reactive hyperemia in healthy children. ${ }^{15}$ The 10th percentile was derived from the normal distribution of values from a population of 105 children and adolescents studied by Järvisalo et al. ${ }^{14}$ and was dilatation of $3.3 \%$. In our study the 10 th percentile was at a dilatation of $6.7 \%$.

Obesity, associated or not with hypercholesterolemia, is a significant cause of endothelial dysfunction. 18,20,23,26-28 As can be seen in our results, nine of the adolescents were obese or dyslipidemic. This fact supports the figure of $6.7 \%$ (the 10th percentile in our study) endothelium-dependent vascular dilatation as the lower limit of normality in adolescents.

There is much evidence that the chronic diseases obesity, non-insulin dependent type II diabetes, systemic arterial hypertension and dyslipidemia have their origin during gestation. A difference of less than $1 \mathrm{~kg}$ in the weight of a newborn infant can correspond to an increase of more or less $3.5 \mathrm{mmHg}$ in pressure systolic in adulthood. 29 Endothelial dysfunction may be associated with birth weight inappropriately low for gestational age rather than with low weight due to prematurity and also with growth rate during the first two weeks of life. 7,25,29 All of the adolescents in the present study were born fullterm and with adequate weight, however we do not have information on their rates of growth during their first weeks of life (Table 1 ).

Elevated lipoprotein-A promotes endothelial dysfunction. In a study by Sorensen et al., total serum cholesterol was inversely related to flow-mediated vascular dilatation, i.e. endothelium-dependent. Among hypercholesterolemic children this was inversely related to lipoprotein-A and not with LDL or HDL fractions. ${ }^{18}$ The adolescents in our study had normal serum lipoprotein-A concentrations.

In a comparative study of patients who had received kidney transplantation and healthy controls, all children and adolescents aged 9 to 19 years, Lilien et al. found endothelium-dependent vascular dilatation levels of $15.6 \pm 6.8 \%$ (mean $\pm 1 \mathrm{SD}$ ) for the controls, ${ }^{22}$ which is similar to the result of the present study, although the age group did include children.

No studies were found in the literature investigated that had selected healthy adolescent individuals and with normotensive parents, as was the case in the present study, which included subjects in the age range of 15 years to 18 years and 8 months. For this reason comparisons have been made with all studies that assessed endothelial function using the technique described by Celermajer et al. ${ }^{6}$ and that had adolescents in their control groups with ages similar to the adolescents in the present study. 
The principal limitation of our study is the small number of adolescents, which is the result of the difficulty of finding individuals with no detectable risks for hypertension and/or cardiovascular diseases. One proposal for reducing this limitation is to undertake multicenter, controlled trials.

The 10th percentile $(6.7 \%)$ on the endotheliumdependent vascular dilatation distribution curve for the adolescents in the present study can be considered the lower limit of normality. The knowledge of this limit is important for the diagnosis of endothelial dysfunctions that precede the onset of systemic arterial hypertension and cardiovascular diseases.

\section{References}

1. Morris ST, Jardine AG. The vascular endothelium in chronic renal failure. J Nephrol. 2000;13:96-105.

2. Celermajer DS. Endotelial dysfunction: does it matter? Is it reversible? JACC. 1997; 30:325-33.

3. Satchell SC, Anderson KL, Mathieson PW. Angiopoeitin 1 and vascular endothelial growth factor modulate human glomerular endothelial cell barrier properties. J Am Soc Nephrol. 2004;15:566-74.

4. Karwatowska-Prokooczuk E, Wenmalm A. Endothelium-derived constricting factor(s): the novelty-endothelin. Clin Physiol. $1990 ; 10: 113-21$

5. Mitchel RN, Cotran RS. Distúrbios hemodinâmicos trombose e choque. In: Cotran RS, Kumar V, Collins T, editores. Patologia estrutural e funcional. $6^{a}$ ed. Rio de Janeiro: GuanabaraKoogan; 2000. p. 101-23.

6. Celermajer DS, Sorensen KE, Gooch VM, Spiegehalter DJ, Miller OI, Sullivan ID, et al. Non-invasive detection of endothelial dysfunction in children and adults at risk of atherosclerosis. Lancet. 1992;340:1111-15.

7. Leeson $C P$, Kattenhorn M, Morley R, Lucas A, Deanfield JE. Impact of low birth weight and cardiovascular risk factors on endothelial function in early adult life. Circulation. 2001;103:1264-8.

8. Zizek B, Poredos P, Vedecnik V. Endothelial dysfunction in hypertensive patients and in normotensive offspring of subjects with essential hypertension. Heart. 2001;85:215-7.

9. Sorensen, KE, Celermajer DS, Spiegelhalter DJ, Georgakopoulus $D$, Robinson J Thomas $O$, et al. Noninvasive measurement of human endothelium dependent arterial responses: accuracy and reproducibility. Br Heart. 1995;74:147-53.

10. Misra A. Risk factors for atherosclerosis in young individuals. J Cardiovasc Risk. 2000;7:215-29.

11. Update on the 1987 Task Force Report on High Blood Pressure in Children and Adolescents: a working group report from the National High Blood Pressure Education Program. Pediatrics. 1996;98:649-58.

12. World Health Organization - Physical Status: the use and interpretation of anthropometry. Geneve: WHO; 1995; (Technical series 854).

13. Tanner JM. Growth at adolescence. 2nd ed. Oxford: Blackwell; 1962.
14. Järvisalo MJ, Rönnemaa T, Volanen I, Kaitosaari T, Kallio K, Hartiala JJ, et al. Brachial artery dilatation responses in healthy children and adolescents. Am J Physiol Heart Circ Physiol. 2002;282:H87-H92.

15. Järvisalo MJ, Raitakari M, Toikka JO, Putto-Laurila A, Rontu R, Laine $S$, et al. Endothelial dysfunction and increased arterial intima-media thickness in children with type 1 diabetes. Circulation. 2004;109:1750-5.

16. Must A, Dallal GE, Dietz WH. Reference data for obesity: 85 and 95 percentiles of body mass index $\left(\mathrm{Wt} / \mathrm{Ht}^{2}\right)-\mathrm{A}$ correction. $\mathrm{Am}$ J Clin Nutr. 1991;53:839-46.

17. IV Diretrizes Brasileiras de Hipertensão Arterial - Sociedade Brasileira de Hipertensão; Sociedade Brasileira de Nefrologia, 2002.

18. Sorensen KE, Celermajer DS, Georgkapoulos D, Hatcher G, Betteridge DJ, Deanfield JE. Impairment of endotheliumdependent dilatation is an early event in children with familial hypercholesterolemia and is related to the lipoprotein (a) level. J Clin Invest. 1994;93:50-5.

19. Dhillon R, Clarkson P, Donald AE, Powe AD, Nash M, Novelli V, et al. Endothelial dysfunction late after Kawasaki Disease. 1996;94:2103-6.

20. Tounian P, Aggoun Y, Dubern B, Varille V, Guy-Grand B, Sidi D, et al. Presence of increased stiffness of the common carotid artery and endothelial dysfunction in severely obese children: a prospective study. Lancet. 2001;358:1400-4.

21. Deng You-Bin, Xiang Hui-Juan, Chang Q, Li Chun-Lei. Evaluation by high-resolution ultrasonography of endothelial function in brachial artery after Kawasaki disease and the effects of intravenous administration of vitamin C. Circ J. 2002;66:908-12.

22. Lilien MR, Stroes ES, Op't Roodt J, de Jongh S, Schröder $\mathrm{CH}$, Koomans HA. Vascular function in children after renal transplantation. Am J Kidney Dis. 2003;41:689-91.

23. de Jongh S, Lilien MR, op't Roodt J, Stroes ES, Bakker HD, Kastelein JJ. Early statin therapy restore endothelial function in children with familial hypercholesterolemia. J Am Col Cardiol. 2002;40:2117-21.

24. Bonnet D, Aggoun Y, Szezepanski I, Bellal N, Blanche S. Arterial stiffness and endothelial dysfunction in HIV-infected children. AIDS. 2004;18:1037-41.

25. Singhal A, Cole TJ, Fewtrell M, Deanfield J, Lucas A. Is lower early growth beneficial for long-term cardiovascular health? Circulation. 2004;109:1108-13.

26. Aggoun Y, Bonnet D, Girardet JP, Brucker E, Polak M, Sidi D. La fonction artérielle des enfants hypercholestérolémiques. Arch Pédiatr. 2001;8 (Suppl 2):S313-5.

27. Hoffman U, Dirisamer A, Heher S, Kostner K, Widhalm K, Neunteufl T. Relation of peripheral flow-mediated vasodilatation and coronary arterial calcium in young patients with heterozygous familial hypercholesterolemia. Am J Cardiol. 2002;90:70-3.

28. Woo KS, Chook P, Yu CW, Sung RY, Qiao M, Leung SS, et al. Effects of diet and exercise on obesity-related vascular dysfunction in children. Circulation. 2004;109:1981-6.

29. Barker DJ. In utero programming of chronic disease. Clin Sci. 1998;95:115-28.

Correspondence:

Zélia M. de Andrade

Rua Joaquim de Almeida, 210/53, Mirandópolis

CEP 04050-010 - São Paulo, SP, Brazil

Tel./Fax: +55 115072.9716

E-mail: zeliandrade@terra.com.br 